\title{
American Geriatrics Society-Beers Criteria and adverse drug reactions: a comparative cross- sectional study of Nigerian and South African older inpatients
}

This article was published in the following Dove Press journal:

Clinical Interventions in Aging

\section{Sule Ajibola Saka \\ Manimbulu Nlooto \\ Frasia Oosthuizen \\ Discipline of Pharmaceutical Sciences, College of Health Sciences, University of KwaZulu-Natal, Westville Campus, Durban 4000, South Africa}

Correspondence: Sule Ajibola Saka Discipline of Pharmaceutical Sciences, College of Health Sciences, University of KwaZulu-Natal, Westville Campus, Private Bag X5400I, Durban 4000, South Africa

Tel +27 732233014

Email sulsak0I@yahoo.com

\begin{abstract}
Background: The Beers Criteria were developed with the aim of improving the safety of medicines among older persons. While the association between the Beers' list of potentially inappropriate medicines (PIMs) and adverse drug reactions (ADRs) among older Caucasians is contentious, the ability of the Criteria to predict ADRs among older persons in Africa remains unexplored.
\end{abstract}

Objectives: This study aimed to compare the prevalence of PIMs and ADRs among hospitalized older persons in Nigeria and South Africa, and to determine the association between the 2015 American Geriatrics Society-Beers (AGS-Beers) PIMs and ADRs.

Methods: The medical records of older persons aged $\geq 60$ years who were hospitalized in teaching hospitals in Nigeria and South Africa were randomly selected, and retrospectively evaluated for ADRs by two clinical pharmacists using the Naranjo algorithm. The PIMs were assessed using the 2015 AGS-Beers Criteria. A multivariate logistic regression was used to determine the associated factors for ADRs among the hospitalized older persons, with $P<0.05$ being considered significant.

Results: The samples which comprised 268 and 339 hospitalized older persons (mean age $70.53 \pm 8.22$; $95 \% \mathrm{CI}-0.21$ to 2.32 vs mean age $69.49 \pm 7.64 ; 95 \% \mathrm{CI}-0.25$ to $2.34, P=0.11$ ) were evaluated in Nigeria and South Africa, respectively. The PIMs among the older persons in Nigeria were $32.1 \%(86 / 268)$ and $30.1 \%(102 / 339$, OR=0.91, 95\% CI $0.64-1.29, P=0.6)$ for South Africa; $13.8 \%$ (37/268) of the hospitalized older persons in Nigeria experienced 43 cases of ADRs compared to 9.1\% (31/339) in South Africa (95\% CI 0.38-1.04, $P=0.07)$. The multivariate analysis showed no association between PIMs and ADRs among the hospitalized older persons in Nigeria $(\mathrm{OR}=1.4895 \%$ CI $0.70-3.17, P=0.31)$ and South Africa $(\mathrm{OR}=1.09$, 95\% CI 0.48-2.49, $P=0.83)$.

Conclusion: The 2015 AGS-Beers PIMs were not associated with ADRs among the hospitalized older persons in Nigeria and South Africa. However, physicians should be cautious when prescribing certain medications in the AGS-Beers list.

Keywords: adverse drug reactions, African older persons, Beers Criteria, inappropriate medicine, hospitalized

\section{Introduction}

Adverse drug reactions (ADRs) are a public health issue that contributes to increased morbidity and mortality among older persons worldwide. ${ }^{1}$ According to the World Health Organization (WHO), an ADR is defined as "a noxious, unintended effect of a medication 
that occurs at doses normally used in man for prophylaxis diagnosis, therapy of diseases, or for the manipulation of physiological functions". ${ }^{2}$ Many explicit criteria including the Beers Criteria, European Union-Potential Inappropriate Medicines, and Screening Tool of Older People's Prescriptions and Screening Tool to Alert to Right Treatments (STOPP/START Criteria) are currently being applied in clinical practice to guide prescriptions among older persons. ${ }^{3-5}$ These criteria provide lists of potentially inappropriate medicines (PIMs), which are believed to contribute to ADRs among older persons. Potential inappropriate medicines are those that are regarded as being high risk or less effective in older persons when used in the presence of safer and more effective alternatives. ${ }^{3}$ The nexus between the PIMs and ADRs among older persons has however remained controversial in the medical literature.

A review of studies that evaluated the associations between the earlier versions of the Beers Criteria and ADRs concluded that there was evidence to support the association. ${ }^{6}$ This is supported by another study that found a significant association between the 2012 sanctioned American Geriatrics Society-Beers (AGS-Beers) Criteria and adverse outcomes among older persons in Switzerland. ${ }^{7}$ Other studies, however, found no association between the 2012 AGSBeers PIMs and ADRs. ${ }^{8-10}$ Another study that compared the Beers and STOPP Criteria reported a moderate prognostic predictive ability of ADRs for both the 2003, 2012 AGSBeers Criteria and the STOPP/START Criteria among older persons in the United States. ${ }^{11}$ However, many clinicians and researchers in Europe appear to identify with the STOPP/ START Criteria which have been reported to predict more ADRs among the continent older persons than the Beers Criteria. ${ }^{12-14}$ However, the literature suggests that in view of the release of the 2015 AGS-Beers Criteria, further studies will be needed to determine the risk of ADRs associated with the updated PIM list. ${ }^{10}$

There is a dearth of studies that have explored the associations between the 2015 AGS-Beers Criteria and ADRs among older persons. However, a recent study in India that applied the 2015 AGS-Beers Criteria to older persons aged $\geq 60$ years reported no association between the updated Beers PIMs and ADRs. ${ }^{15}$ Another study in the United States associated falls among a Parkinson's disease population with the PIMs that are recommended to be avoided in patients with a history of falls in the 2015 AGS-Beers Criteria. ${ }^{16}$

Many ADR causality assessment tools are currently available to assist clinicians to evaluate ADRs, especially among older persons in whom identification of ADRs usually poses a challenge. ${ }^{17}$ The Naranjo algorithm is among the most commonly applied tools in clinical practice, ${ }^{18}$ being easier to use than many other tools, and adjudged to have a high specificity and sensitivity. ${ }^{17,18}$ A recent study that evaluated how well the Naranjo algorithm categorized ADRs among Japanese reported that the algorithm had a specificity of 0.95 and sensitivity of $0.59 .{ }^{19}$ It is a questionnaire-based algorithm that determines the probability of ADR occurrence based on defined scores, and classifies them into "definite", "probable", "possible", and "doubtful". ${ }^{20}$ In addition, the use of triggers, such as the Institute for Healthcare Improvement (IHI) global trigger tool has been found useful in retrospective evaluations of ADRs among inpatients in many health care settings as they provide clues that assist in identifying ADRs. ${ }^{21}$

In Africa, including Nigeria and South Africa, the Beers Criteria have been the most applied explicit criteria for evaluating the quality of prescribing among older persons. A review of interventions to reduce ADRs among older persons in Africa showed that more than three-quarters of the studies applied the Beers Criteria. ${ }^{22}$ However, to the best of the authors' knowledge, no study has evaluated associations between the Beers Criteria and ADRs among older persons in Africa. There are conflicting reports on the associations between the earlier itinerary of the Beers Criteria and ADRs among older Caucasians, but only little information is available about the Criteria PIMs and ADRs among older Africans. Therefore, this study aimed to compare the prevalence of PIMs and ADRs among hospitalized older persons in Nigeria and South Africa, and to determine the associations between the 2015 AGS-Beers PIMs and ADRs.

\section{Methods}

\section{Study design, sites, and setting}

This was an epidemiological cross-sectional study that utilized a medical chart review among hospitalized older persons. Patients' medical records were randomly selected, and the charts were retrospectively reviewed for ADRs. The study was carried out in two internal medicine wards, each in a university public teaching hospital in a cosmopolitan city, in both Nigeria and South Africa. The two hospitals provided tertiary health care services and were referral centers for many other health care facilities in the regions in which they are located. The hospitals had no standard protocol to detect or monitor ADRs, and no dedicated geriatric wards at the time of this study between 13th April and 25th November, 2017. However, there were specialists in geriatrics consulting in the medical wards of the two hospitals. 


\section{Study population/eligibility criteria}

This study eligibility included older persons aged $\geq 60$ years who were hospitalized in the internal medicine wards of the two hospitals between 1st January and 31st December, 2016. The age is in line with the United Nations definition of older persons for developing countries, ${ }^{23}$ and is consistent with previous studies on ADRs in low and middle-income countries. ${ }^{8,10,15,24}$ Hospitalized older persons without complete demographic information and missing charts, or who were discharged, transferred to intensive care, readmitted, or who died within 24 hours of hospitalization were excluded.

\section{Sample size estimation}

A total of 846 eligible older persons' medical records were available for selection in Nigeria, based on the inclusion criteria. The sample size was calculated using a formula previously described. ${ }^{25}$ Using a $50 \%$ response distribution, a margin of error of $5 \%$ and a power of $95 \%$, a minimum sample size of 265 was calculated. With an additional 10\% included for attrition, a maximum sample size of 292 was calculated. The number of records required in South Africa was calculated using the same formula as in Nigeria, but with a population of 20,000 and the same response distribution, margin of error and power, resulting in a minimum sample size of 377 , with $10 \%$ attrition being added to give a maximum sample size of 415 .

\section{Selection of study populations}

The study populations in Nigeria and South Africa were identified from the hospital admission records office. The patients' file numbers were listed, and eligible records selected using a simple randomization technique with the aid of computer-generated random numbers. No blinding was applied in selecting the patients' medical chart records. The same sampling procedure used in Nigeria was repeated on the South African sample for internal consistency.

\section{Data collection}

A checklist that had been pretested was used to capture patients' information: sociodemographics, sociomedical, and medication histories, medicine prescriptions during hospitalization, and dates of admission and discharge/death. It also captured patients' specific baseline laboratory parameters obtained at hospitalization and during the hospital stay. The laboratory data/parameters of interest included estimated glomerular filtration rate (eGFR; $\left.\mathrm{mL} / \mathrm{min} / 1.73 \mathrm{~m}^{2}\right)$ or serum creatinine $(\mathrm{mg} / \mathrm{dL}$ ), serum electrolytes (potassium $[\mathrm{mmol} / \mathrm{L}]$ and sodium $[\mathrm{mmol} / \mathrm{L}])$, and platelet counts $\left(\right.$ cells $\left./ \mathrm{mm}^{3}\right)$, where available. The attending physicians' notes on ADR occurrence in patients as documented in the patients' records, and the clinical decisions that were taken to mitigate them, including a reduction in dosage, stoppage of the medication, and the use of other medications to counteract the effect of the offending medications were also extracted.

\section{Study procedure}

\section{Evaluation of ADRs among the older persons}

ADRs among the study population were assessed using a multifaceted approach including a comprehensive review of the physicians' and nursing charts. Attention was paid to patients verbalized complaints documented in the charts. Changes in patients' baseline-laboratory data and other clinical parameters during the inpatient care were evaluated. Radio imaging data, such as echocardiography, ultrasound, and electrocardiogram parameters were however not considered for review. Although the radio imaging parameters were part of the baseline data for the admitted patients, the procedures were rarely ordered by the physicians during the inpatients' care, making it impracticable to evaluate ADRs due to certain medications. ADRs due to neoplastic agents or infusions were not evaluated in this study.

The medical charts were independently reviewed by two clinical pharmacists using the IHI global tool for measuring ADRs. ${ }^{21}$ The triggers found during the review were documented irrespective of whether they detected the actual ADRs or not. The suspected ADRs were evaluated for causality using the Naranjo algorithms which comprises of ten weighted questions with "yes", "no", or "do not know" as responses. ${ }^{20}$ Each of the responses is assigned different point values $(-1$ to +2$)$, the total scores for an assessment ranging from -4 to -13 . The total score for each suspected ADR encounter was calculated and the causal relationship determined. The suspected ADR was considered as definite when the total score is $\geq 9$, probable when it is between 5 and 8 , possible when it is from 1 to 4 , and doubtful when it is $\leq 0$. Where disagreements occurred between the assessors, the cases were referred to an internal physician and consensus reached. In cases where the attending physicians documented specific ADRs (not inferred from the treatment), only one of the assessors had to agree with the attending physicians.

In this study, the PIMs listed in the 2015 AGS-Beers Criteria were evaluated for both predictable and unpredictable ADRs, though the criteria were meant to mitigate predictable/preventable ADRs. However, associations were determined between the PIMs and predictable ADRs with 
only "possible" and "probable" categories of ADRs being considered for further analysis.

The independent variables assessed in this study included age group ( $<80$ years and $\geq 80$ years), gender, comorbidity index $(<4.0$ and $\geq 4.0$ ), length of hospital stay ( $<12$ days and $\geq 12$ days), exposure to the 2015 AGS-Beers PIMs, presence of musculoskeletal and urogenital disorders, exposure to psychoanaleptics (N06CA01) and anti-inflammatory, antirheumatic NSAIDs (M01A). The patients' ages, as documented by the physicians, were used while the length of hospital stay was determined from the date of admission and discharge/death, as recorded in the patients' charts. The age-adjusted Charlson's comorbidity index for patients' preexisting diseases was calculated using the formula previously described. ${ }^{26}$ A comorbidity index of $\geq 4$ and age $\geq 80$ years were used as references in line with a study that found associations between these reference values and ADRs among older persons. ${ }^{27}$ The reference of $\geq 12$ days was used to define the duration of hospital stay in conformity with previous studies. ${ }^{10,28}$

\section{Evaluation of PIMs}

The PIMs were evaluated using the full application of the 2015 AGS-Beers Criteria. The patients' latest eGFR/serum creatinine data were considered in evaluating PIMs due to kidney functions. Medication utilization during hospitalization was extracted with generic names and presented using the Anatomical Therapeutic Chemical (ATC) classification system. Patients' current diagnosis for which they received medications was classified using the ICD10, version 2016.

\section{Ethical consideration}

This study was conducted after ethics approval was obtained from the University of KwaZulu-Natal Biomedical Research Ethics Committee (BE 591/16) and the hospital research ethics committees of both study sites. Consent was also obtained from the heads of the medical departments. The study was granted an exemption from patients' consents as it entailed a chart review. The identities of the participants were anonymized, with unique codes being used for patients' identities, and access to the codes and data being secured through a password. Only authorized personnel stated in the ethics document have access to the code and the data.

\section{Data management analysis}

The data were manually cleaned and analyzed using the SPSS, version 25 software, primarily using descriptive statistics. The Student's independent $t$-test was used to compare the means of normally distributed continuous variables. The results were presented in means and SDs with 95\% CI. Records with a missing value were excluded before analysis. A comparison was made between patients' variables in Nigeria and South Africa using a Pearson chi-squared test (or Fisher's exact as appropriate).

A univariate analysis was carried out to identify factors associated with ADRs in each geo-facility using Pearson chi-squared test. A multivariate logistic regression model was built, with confounding variables including comorbidity, use of NSAIDs, and duration of hospital stay being tested. Only variables with $P<0.05$ in the univariate analysis were retained in the final model. Exposure to PIM was however forced into the model. The Hosmer-Lemeshow goodness of fit was used to assess the adequacy of the final models. The results were presented using OR with $95 \%$ CI with $P<0.05$ being considered significant.

\section{Results}

\section{The outcome of the selection of the study population}

Figure 1 describes the outcome of the selection process of the patients' medical records. A total of 846 and 1,236 records of eligible hospitalized older persons were available for sampling in Nigeria and South Africa, respectively.

Table 1 presents the clinical and sociodemographic characteristics of the study populations in Nigeria and South Africa. A total of 292 records were selected in Nigeria, of which 268 (91.8\%) were evaluated, and 415 records in South Africa, of which 339 (81.7\%) were evaluated. The hospitalized older persons in Nigeria and South Africa had mean ages of $70.53 \pm 8.22$ years (95\% CI -0.21 to 2.32 ) and $69.49 \pm 7.64$ years, $(95 \% \mathrm{CI}-0.25$ to $2.34, P=0.11)$, respectively. The study population in South Africa included the indigenous Africans (239, 70.5\%), Asian descent (38, 11.2\%), Khoisan descent (23, 6.8\%), and European descent $(39,11.5 \%)$ populations. Musculoskeletal disorders $(23 / 268,8.6 \%$ vs $32 / 339,9.4 \%)$ and urinary diseases $(22 / 268,8.2 \%$ vs $28 / 339,8.3 \%)$ were almost of equal distribution among the cohorts in Nigeria and South Africa, respectively.

Table 2 presents the PIMs in Nigeria and South Africa according to the ATC classification. Almost one-third of the older persons evaluated in Nigeria (86/268, 32.1\%) and South Africa $(102 / 339,30.1 \%)$ received at least one PIM during hospitalization, as per the 2015 AGS-Beers Criteria (OR=0.91, 95\% CI 0.64-1.29, $P=0.6$; Table S1). There were no significant differences in PIM exposure among the races in South Africa $(P=0.74)$. 


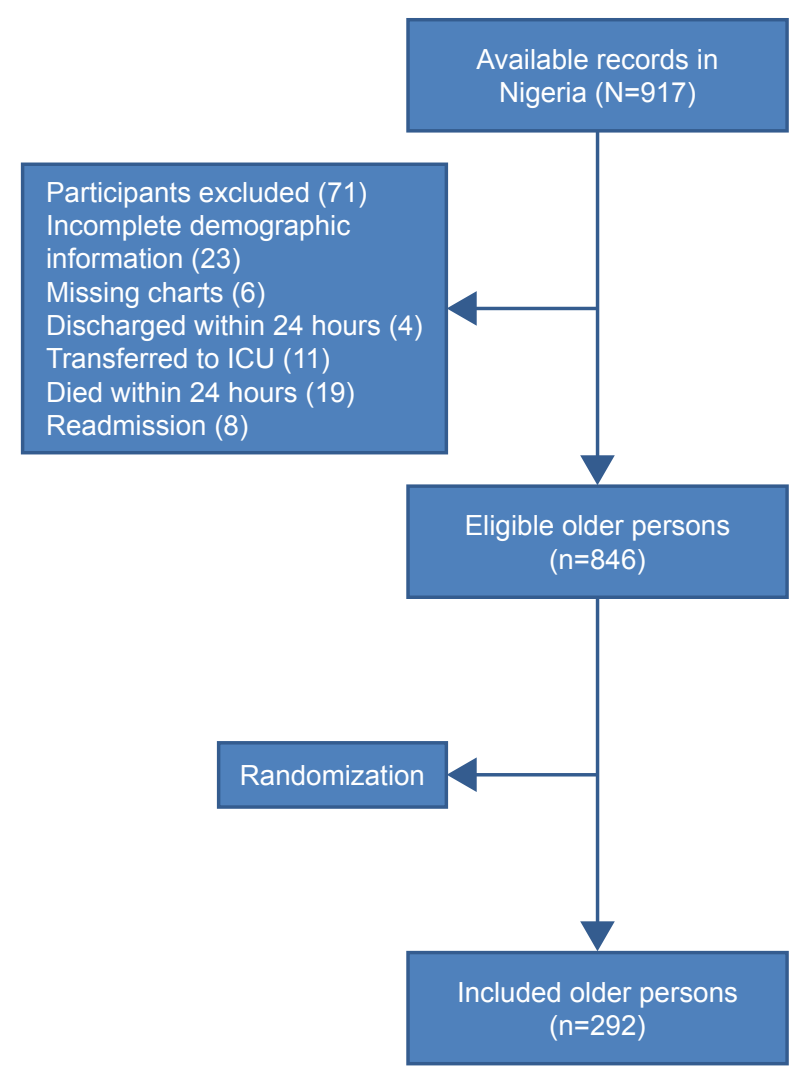

Figure I Flowchart depicting the selection process of the included older persons. Abbreviation: ICU, intensive care unit.

Table 3 presents the triggers found in the records of older persons evaluated in Nigeria and South Africa. The IHI tool provided triggers for suspected ADRs in Nigeria (67/268, $25.0 \%)$ and $(86 / 339,25.4 \%)$ South Africa. The level of correlations of IHI trigger with ADRs among hospitalized older persons in Nigeria was $P=0.045$ and in South Africans was $P=0.72$.

Table 4 presents the organ systems affected by the ADRs and the offending medications among the older persons investigated in Nigeria and South Africa. The hospitalized older persons in Nigeria (37/268, 13.8\%) experienced 43 cases of ADRs, while the South Africans had $31(31 / 339,9.1 \%)$ within the study period $(95 \% \mathrm{CI}$ $0.38-1.04, P=0.07)$, with no significant racial difference $(P=0.91)$. Of the total observed cases, only $9.3 \%(4 / 43)$ in Nigeria and $6.5 \%(2 / 31)$ in South Africa were formally documented as ADRs. Among the Nigerians, constipation $(8 / 43,18.6 \%)$ secondary to chlorpromazine, amitriptyline, tramadol, and diclofenac was observed, and in South Africa confusion $(6 / 31,19.4)$ was secondary to opioid and benzodiazepines administration.

PIMs were responsible for only $34.9 \%$ (15/43) and 32.3\% (10/31) ADR cases in Nigeria and South Africa, respectively (Table S2). The Naranjo algorithm measurement of the ADRs
Available records in

South Africa $(\mathrm{N}=1,498)$

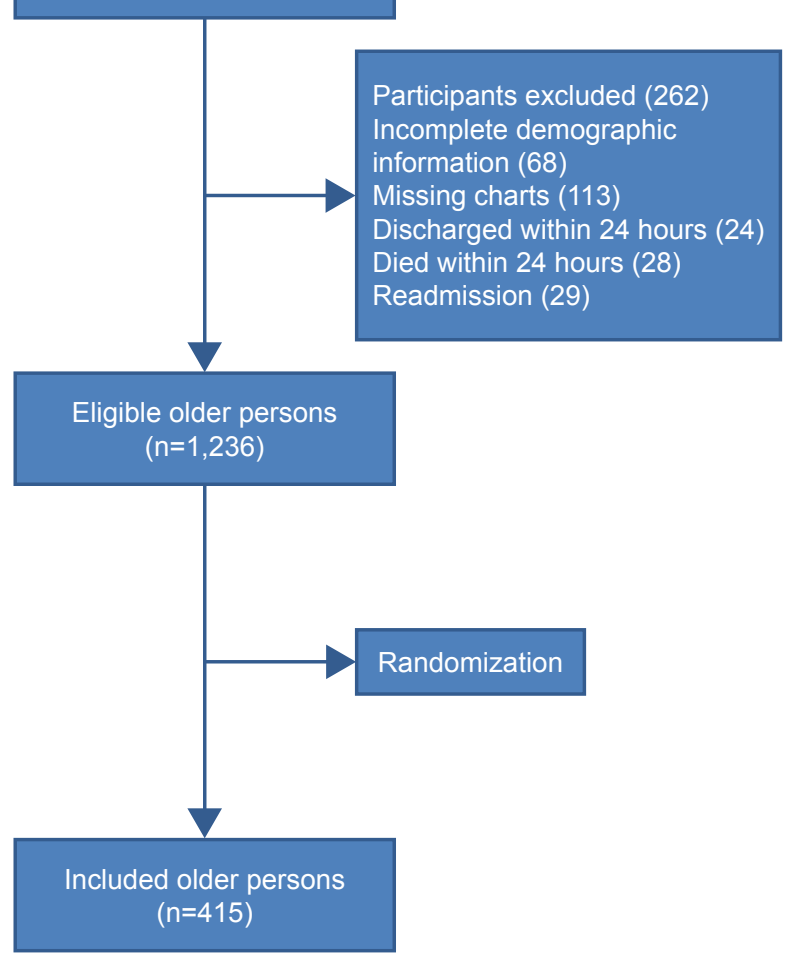

showed that $90.7 \%(39 / 43)$ Nigerian and $83.9 \%(26 / 31)$ South African cases were of probable ADR categories, while the remaining ADRs in Nigeria (4/43, 9.3\%) and South Africa $(5 / 31,16.1 \%)$ were possible ADRs.

\section{Associations between independent variables and ADRs}

Table 5 presents the associations between independent variables and ADRs. There was a significant difference in mean ages of older persons investigated in Nigeria with ADRs vs No ADRs being 67.49 \pm 7.81 years vs $71.02 \pm 8.20$ years, respectively ( $95 \%$ CI $0.69-6.37, P=0.02$ ). The length of hospital stays was $2.22 \pm 1.58$ days vs $1.49 \pm 0.99$ days, respectively $(95 \% \mathrm{CI}-1.11$ to $0.35, P<0.001)$. The univariate analysis showed the presence of musculoskeletal disorders, exposure to psychoanaleptic medications, and duration of stay $\geq 12$ days as being associated with ADRs in Nigeria.

The mean ages of the South African with ADRs vs No ADRs were not significantly different $(69.65 \pm 7.17$ years vs $69.46 \pm 7.70$ years, respectively, $95 \% \mathrm{CI}-3.0$ to $2.65, P=0.9$ ). The length of hospital stays for those who experienced ADRs vs No ADRs in South Africa was $1.26 \pm 0.45$ days vs $1.35 \pm 0.64$ days, respectively ( $95 \% \mathrm{CI}-0.14$ to $0.32, P=0.45$ ). 
Table I Characteristics of the older persons investigated in the study

\begin{tabular}{|c|c|c|c|c|}
\hline Variable & Grouping & $\begin{array}{l}\text { Nigeria, } \\
\text { n (\%) }\end{array}$ & $\begin{array}{l}\text { South Africa, } \\
\text { n (\%) }\end{array}$ & $P$-value \\
\hline Age $($ mean $\pm S D)$ & & $70.53 \pm 8.22$ years & $69.49 \pm 7.64$ years & 0.10 \\
\hline \multirow[t]{4}{*}{ Age classification } & $60-69$ years & $135(50.4)$ & $196(57.8)$ & \\
\hline & $70-79$ years & $93(34.7)$ & $102(30.1)$ & 0.29 \\
\hline & $80-89$ years & $31(11.6)$ & $34(10.0)$ & \\
\hline & $\geq 90$ years & $9(3.3)$ & $7(2.1)$ & \\
\hline \multirow[t]{2}{*}{ Gender } & Female & $122(45.5)$ & $188(55.5)$ & \\
\hline & Male & I $46(54.5)$ & I5I (44.5) & 0.02 \\
\hline \multirow[t]{2}{*}{ Marital status } & Single & $109(40.7)$ & $190(56.0)$ & \\
\hline & Married & $159(59.3)$ & $149(44.0)$ & $<0.001$ \\
\hline Comorbidity index (mean \pm SD) & & $3.82 \pm 1.21$ & $4.68 \pm 2.14$ & $<0.001$ \\
\hline \multirow[t]{2}{*}{ Patients' comorbidity index } & $<4.0$ & $104(38.8)$ & $115(33.9)$ & \\
\hline & $\geq 4.0$ & $164(61.2)$ & $224(66.1)$ & 0.21 \\
\hline \multirow[t]{8}{*}{ Comorbidity } & Circulatory system & III (4I.4) & $64(18.5)$ & \\
\hline & Endocrine system & $10(3.7)$ & $47(13.8)$ & \\
\hline & Musculoskeletal system & $23(8.6)$ & $32(9.4)$ & 0.93 \\
\hline & Neoplasm & $24(9.0)$ & $74(21.8)$ & \\
\hline & Genitourinary system & $22(8.2)$ & $28(8.3)$ & \\
\hline & Digestive system & $18(6.7)$ & $16(4.7)$ & \\
\hline & Infectious diseases & $23(8.6)$ & $17(5.0)$ & \\
\hline & Others $^{\mathrm{a}}$ & $37(13.8)$ & $61(18.0)$ & \\
\hline Mean duration of hospital stay (mean $\pm \mathrm{SD})$ & & $|\mathrm{I} .47 \pm| 3.3 \mid$ days & $7.30 \pm 6.5$ days & $<0.001$ \\
\hline \multirow[t]{4}{*}{ Duration of hospital stay } & $2-9$ days & $179(66.8)$ & $245(72.3)$ & \\
\hline & 10-19 days & $55(20.5)$ & $78(23.0)$ & \\
\hline & 20-29 days & $18(6.7)$ & $13(3.8)$ & 0.005 \\
\hline & $\geq 30$ days & $16(6.0)$ & $3(0.9)$ & \\
\hline
\end{tabular}

Note: a Other systems include skin, respiratory, nervous, mental, and behavioral, eye diseases and diseases affecting more than I system.

There were no significant correlations between races and age $(P=0.15)$, comorbidity index $(P=0.77)$, PIM exposure $(P=0.34)$, ADRs $(P=0.07)$, and duration of hospital stay $(P=0.51)$ in South Africa.

\section{Discussion}

\section{Main findings}

This study compared ADRs and PIMs among hospitalized older persons in Nigeria and South Africa and evaluated

Table 2 The classification of PIM received by the older persons in Nigeria and South Africa

\begin{tabular}{l|l|l|l}
\hline Pharmacological classification & ATC classification & Nigeria, n (\%) & South Africa, n (\%) \\
\hline Antidepressants & N06A & $8(9.3)$ & $10(9.8)$ \\
Opioids & N02A & $10(11.6)$ & I (I.0) \\
Antidiabetics & Al0 & $4(4.7)$ & $27(26.5)$ \\
Antihistamine (systemic use) & R06A & $1(1.2)$ & $8(7.8)$ \\
Anti-inflammatory, antirheumatic, NSAIDs & M0IA & $19(22.1)$ & $24(23.5)$ \\
Psychoanaleptics & N06CA0I & $2(2.3)$ & $0(0.0)$ \\
Psycholeptics & N05 & $6(7.0)$ & $6(5.9)$ \\
Cardiovascular agents & C & $34(39.5)$ & $11(10.7)$ \\
Drugs for gastrointestinal disorders & A03 & $2(2.3)$ & $15(14.7)$ \\
Total & & $86(100.0)$ & $102(100.0)$ \\
\hline
\end{tabular}

Abbreviations: ATC, Anatomical Therapeutic Chemical; PIM, potentially inappropriate medicine. 
Table 3 The triggers for identifying suspected ADRs

\begin{tabular}{|c|c|c|}
\hline Trigger & $\begin{array}{l}\text { Nigeria, } \\
\text { n (\%) }\end{array}$ & $\begin{array}{l}\text { South } \\
\text { Africa, } \\
\text { n (\%) }\end{array}$ \\
\hline Decreased glucose level $<50 \mathrm{mg} / \mathrm{dL}$ & $6(2.2)$ & II (3.2) \\
\hline Serum creatinine rising twice over baseline & $3(1.1)$ & $6(1.8)$ \\
\hline Use of antiemetics & $18(6.7)$ & $26(7.7)$ \\
\hline Over sedation & $4(1.5)$ & $12(3.5)$ \\
\hline Abrupt stoppage of medication & $18(6.7)$ & $12(3.5)$ \\
\hline Potassium level below $2.5 \mathrm{mmol} / \mathrm{L}$ & $7(2.6)$ & II (3.2) \\
\hline Potassium above $5.1 \mathrm{mmol} / \mathrm{L}$ & $6(2.2)$ & $2(0.6)$ \\
\hline Sodium level below $135 \mathrm{mmol} / \mathrm{L}$ & $\mathrm{I}(0.4)$ & $4(1.2)$ \\
\hline Others $^{\mathrm{a}}$ & $4(1.5)$ & $2(0.6)$ \\
\hline No trigger found & $20 I(75.0)$ & $253(74.6)$ \\
\hline Total & $268(100.0)$ & $339(100.0)$ \\
\hline
\end{tabular}

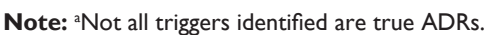

Abbreviation: ADRs, adverse drug reactions.

possible associations between PIMs and ADRs. However, no significant difference in PIMs and ADRs was found among hospitalized older persons evaluated in Nigeria and South Africa. Although the ADRs were not significantly associated with the 2015 AGS-Beers PIMs in both countries, psychoanaleptic medications were identified as being associated with ADRs among the Nigerians in the univariate analysis. The diseases of the musculoskeletal system were associated factors for ADRs among hospitalized older persons in Nigeria, but not in South Africa.

\section{Comparison with previous studies}

This study found no significant differences in the ADRs between hospitalized older persons in Nigeria and South Africa, despite the difference in the mean number of days spent in the hospital between the cohorts. However, other studies have associated length of hospital stay with ADRs. ${ }^{1,10}$ The prevalence of ADRs in the Nigerians (13.8\%) and South Africans (9.1\%) cohorts was lower than previously reported among hospitalized older Italians $(25.0 \%)$ and Brazilians (21.1\%). ${ }^{10,29}$ The result of this study compares with the global prevalence of ADRs (11.5\%) reported among hospitalized older persons. ${ }^{30}$ However, variations in the definition of older persons and methods of assessing ADRs can contribute to the different prevalence reported elsewhere. These variations are well-documented in the literature. ${ }^{27,30,31}$

This study, found no significant difference in PIMs between the Nigerian and South African cohorts, or any significant association between the 2015 AGS-Beers PIMs and ADRs. The finding agrees with similar studies that applied the 2012 AGS-Beers Criteria among older Japanese, Italians, and Brazilians, ${ }^{8-10,32}$ and are consistent with a recent study that applied the 2015 AGS-Beers Criteria among Indian older persons. ${ }^{15}$ However, the present finding contradicts reports of studies that found an association between the 2012 AGSBeers Criteria and ADRs. ${ }^{7,33,34}$

While the 2015 AGS-Beers PIMs were generally not associated with ADRs among the hospitalized older persons at both study sites, a univariate analysis identified psychoanaleptic medications as associated factors for ADRs in Nigeria, similar to finding among French older persons. ${ }^{34}$ Psychoanaleptics (N06CA01) including antidepressants and psycholeptic medications contribute to increased incidence of falls and reduction in the quality of life among older persons. ${ }^{35}$ Physicians should, therefore, be vigilant when prescribing this class of medications to older persons.

Gastrointestinal bleeding was observed among the study population on NSAIDs in both study sites, and this can be potentially dangerous among older persons. The 2015 AGSBeers Criteria recommend that long-term use of NSAIDs without gastroprotective agents be avoided in this cohort. ${ }^{3} \mathrm{~A}$ case of acute kidney injury (AKI) was observed in Nigeria (due to NSAIDs) and South Africa (due to herbal medicine use). AKI is a serious ADR in this age group and efforts should be geared toward preventing their occurrence. ${ }^{36}$ The cases in this study underscore the importance of taking a medication history before prescribing. Prescribers therefore, need to be cautious when prescribing NSAIDs for older persons, and improve on the practice of medication history assessment and documentation, especially in developing countries where herbal medicines are a part of the health care culture.

The diseases of the musculoskeletal system were consistently associated with ADRs among Nigerians, but not South Africans. This is possibly the first study to associate musculoskeletal disorders with ADRs among hospitalized older persons. Previous studies identified neoplasm, diseases of the urinary system, and circulatory system disorders as risk factors for ADRs among hospitalized older persons. ${ }^{10,30,37}$ Although the diseases identified by other studies are also presented in this study, they were not associated with ADRs. Age $\geq 80$ years and comorbidity index $\geq 4$.0 were not associated with ADR in this study in contrast with previous reports. ${ }^{27,28}$

\section{Clinical implications}

ADRs constitute a growing burden to older persons and health care system worldwide and is associated with poor clinical outcomes and increased health care costs. ${ }^{10,14}$ Interventions to reduce ADRs among older persons are therefore of utmost clinical priority. The lack of association between 
Table 4 The ADRs and the offending medications among older persons

\begin{tabular}{|c|c|c|c|c|}
\hline $\begin{array}{l}\text { Systems affected by } \\
\text { the ADRs }\end{array}$ & $\begin{array}{l}\text { Nigeria, } \\
\text { n (\%) }\end{array}$ & Offending medication & $\begin{array}{l}\text { South Africa, } \\
\text { n (\%) }\end{array}$ & Offending medications \\
\hline Digestive system & $22(51.2)$ & & $9(24.3)$ & \\
\hline Constipation & 7 & $\begin{array}{l}\text { Chlorpromazine (I), tramadol (3), } \\
\text { diclofenac (2), amitriptyline (I) }\end{array}$ & 1 & Metoclopramide (I) \\
\hline Vomiting & 5 & $\begin{array}{l}\text { Tramadol (I), pentazocine (2), } \\
\text { atorvastatin (I), digoxin (I) }\end{array}$ & 2 & Ciprofloxacin (I), tramadol (I) \\
\hline Diarrhea & 5 & $\begin{array}{l}\text { Ceftriaxone (2), isoniazid (I), } \\
\text { lisinopril (I), diclofenac (I) }\end{array}$ & - & - \\
\hline GIT bleeding & 5 & Diclofenac (4), aspirin (I) & 5 & Ibuprofen (5) \\
\hline Hepatitis & - & - & 1 & Rifafour (I) \\
\hline Vascular system & $10(23.3)$ & & $8(21.6)$ & \\
\hline Hyperkalemia & 5 & Lisinopril (3), digoxin (2) & 1 & Furosemide (I) \\
\hline Hypotension & 3 & Methyldopa (2), nifedipine (I) & 3 & Amiodarone (I), morphine (I), prazosin (I) \\
\hline Epistaxis & 1 & Warfarin & 1 & Warfarin (I) \\
\hline Thrombocytosis & 1 & Heparin & - & - \\
\hline High blood pressure & - & - & 1 & Pantoprazole (I) \\
\hline Hypokalemia & - & - & 1 & Hydrochlorothiazide (I) \\
\hline Hyponatremia & - & - & 1 & Enalapril (I) \\
\hline Endocrine system & $3(7.0)$ & & $4(10.8)$ & \\
\hline Hypoglycemia & 3 & Insulin (3) & 3 & Insulin (2), insulin sliding scale (I) \\
\hline Metabolic change & - & - & & Metformin (I) \\
\hline Genitourinary system & $2(4.7)$ & & $\mathrm{I}(2.7)$ & \\
\hline AKI & 1 & Diclofenac & 1 & Herbal medicine $(\mathrm{I})$ \\
\hline Urinary retention & 1 & Timolol & - & - \\
\hline Nervous system & $5(11.6)$ & & $9(24.3)$ & \\
\hline Encephalopathy & 1 & Furosemide & - & - \\
\hline Fall & 1 & Tramadol & - & - \\
\hline Gait impairment & 1 & Amitriptyline & - & - \\
\hline Complex partial seizure & 1 & Chlorpromazine & - & - \\
\hline Sedation & 1 & Bromazepam & 3 & $\begin{array}{l}\text { Midazolam + fentanyl (I), lorazepam (I), } \\
\text { dormicum (I) }\end{array}$ \\
\hline Confusion & - & - & 6 & $\begin{array}{l}\text { Haloperidol (I), morphine (I), adrenaline (I), } \\
\text { risperidone (2), tramadol (I) }\end{array}$ \\
\hline Cutaneous (skin) & $\mathrm{I}(2.3)$ & & $0(0.0)$ & \\
\hline Stephen Johnson syndrome & 1 & Spironolactone & - & - \\
\hline Total & $43(100.0)$ & & $31(100.0)$ & \\
\hline
\end{tabular}

Abbreviations: ADRs, adverse drug reactions; AKI, acute kidney injury; GIT, gastrointestinal tract.

the 2015 AGS-Beers Criteria PIMs and ADRs in this study indicates that avoiding the Criteria PIMs may not be sufficient to reduce ADRs among older persons. Physicians should, therefore, consider other interventions in addition to the AGS-Beers PIMs when prescribing to older persons. The present study suggests that with proper monitoring and good clinical practice, the length of hospital stay may not be a significant determinant of ADRs among older persons. The finding also highlights the need for clinicians to be vigilant when prescribing medications to older persons with musculoskeletal diseases.

\section{Strengths and limitations of the study}

This study's strengths were it applied both objective criteria and triggers tool to identify ADRs, which will provide more reliability and detection. It provided information about other predictors for ADRs among older persons apart from PIMs. It was a comparative study in the two countries with the largest population of older persons in Africa. The findings of the study may, therefore, be relevant in other African and developing countries.

Its limitations were while a few medications that could prolong QT interval were prescribed in both health care 


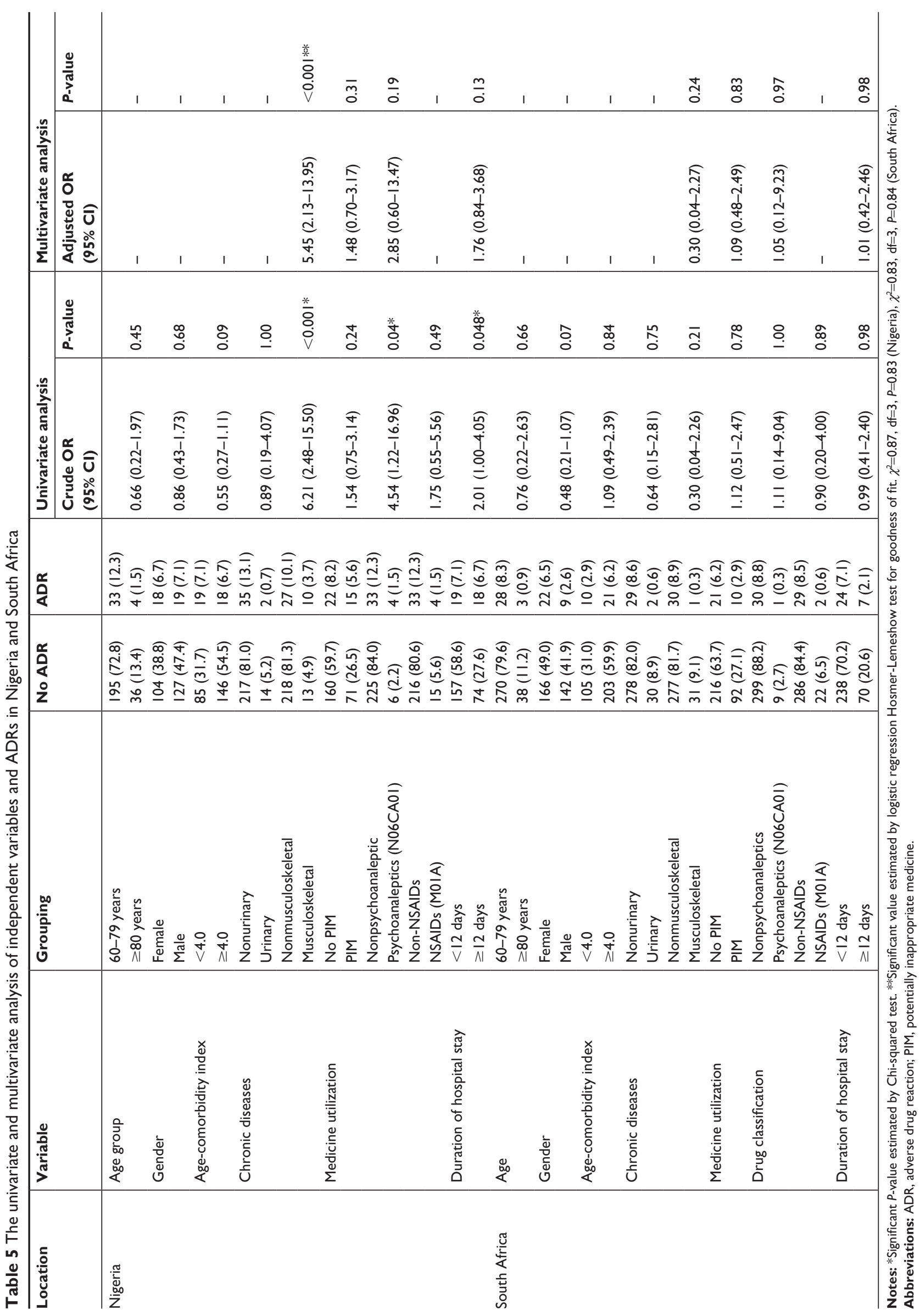


settings, radio imaging data which could have provided information about ADR occurrence due to these medications were not evaluated. The study was retrospective and could therefore have been affected by shortcomings in data collection and recording in the medical charts. Furthermore, not all the participants were managed by geriatricians. The study involved only hospitalized older persons in teaching hospitals, with the South African study population not being stratified. Despite the study strengths, these factors may limit the generalizations of the study findings to other settings.

\section{Conclusion}

The prevalence of PIMs and ADRs in the Nigerian and South African cohorts was similar. While the 2015 AGS-Beers PIMs were not significantly associated with ADRs in both countries, the presence of musculoskeletal system disorders were predictors for ADRs in Nigeria. A multidimensional approach should be adopted to prevent/reduce ADRs among older persons. Prospective and multicentered studies may be needed to validate the finding of this study.

\section{Disclosure}

The authors report no conflicts of interest in this work.

\section{References}

1. Davies EA, O'Mahony MS. Adverse drug reactions in special populations - the elderly. Br J Clin Pharmacol. 2015;80(4):796-807.

2. World Health Organization. Safety of medicines: a guide to detecting and reporting adverse drug reactions; 2002. Available from: http://apps. who.int/medicinedocs/en/d/Jh2992e/. Accessed October 1, 2018.

3. American Geriatrics Society 2015 Beers Criteria Update Expert Panel. American Geriatrics Society 2015 updated beers criteria for potentially inappropriate medication use in older adults. J Am Geriatr Soc. 2015;63(11):2227-2246.

4. Gallagher P, Ryan C, Byrne S, Kennedy J, O’Mahony D, Stopp O'Mahony D. STOPP (Screening Tool of Older Person's Prescriptions) and START (Screening Tool to Alert doctors to Right Treatment). Consensus validation. Int J Clin Pharmacol Ther. 2008;46(2):72-83.

5. Renom-Guiteras A, Meyer G, Thürmann PA. The EU(7)-PIM list: a list of potentially inappropriate medications for older people consented by experts from seven European countries. Eur J Clin Pharmacol. 2015; 71(7):861-875.

6. Jano E, Aparasu RR. Healthcare outcomes associated with beers' criteria: a systematic review. Ann Pharmacother. 2007;41(3):438-448.

7. Reich O, Rosemann T, Rapold R, Blozik E, Senn O. Potentially inappropriate medication use in older patients in Swiss managed care plans: prevalence, determinants and association with hospitalization. PLoS One. 2014;9(8):e105425.

8. Galli TB, Reis WC, Andrzejevski VM. Potentially inappropriate prescribing and the risk of adverse drug reactions in critically ill older adults. Pharm Pract. 2016;14(4):818.

9. Ishii S, Kojima K, Ezawa K, et al. The association of change in medication regimen and use of inappropriate medication based on beers criteria with adverse outcomes in Japanese long-term care facilities. Geriatr Gerontol Int. 2017;17(4):591-597.
10. de Figueiredo TP, de Souza Groia RC, Barroso SCC, do Nascimento MMG, Reis AMM. Factors associated with adverse drug reactions in older inpatients in teaching hospital. Int J Clin Pharm. 2017; 39(4):679-685.

11. Brown JD, Hutchison LC, Li C, Painter JT, Martin BC. Predictive validity of the Beers and Screening Tool of Older Persons' Potentially Inappropriate Prescriptions (STOPP) Criteria to detect adverse drug events, hospitalizations, and emergency department visits in the United States. J Am Geriatr Soc. 2016;64(1):22-30.

12. Corsonello A, Pranno L, Garasto S, Fabietti P, Bustacchini S, Lattanzio F. Potentially inappropriate medication in elderly hospitalized patients. Drugs Aging. 2009;26 Supp1 1:31-39.

13. Hamilton H, Gallagher P, Ryan C, Byrne S, O'Mahony D. Potentially inappropriate medications defined by STOPP criteria and the risk of adverse drug events in older hospitalized patients. Arch Intern Med. 2011;171(11):1013-1019.

14. Levy HB, Marcus EL, Christen C. Beyond the beers criteria: a comparative overview of explicit criteria. Ann Pharmacother. 2010;44(12): 1968-1975.

15. Rawat RS. Evaluation of potentially inappropriate medication use and risk of adverse drug reactions in hospitalized older adults: an observational study in a tertiary care hospital. Int J Pharm Res. 2018; 11(2):79-85.

16. Yusupov E, Chen D, Krishnamachari B. Medication use and falls: applying Beers criteria to medication review in Parkinson's disease. SAGE Open Med. 2017;5(4):205031211774367-7.

17. Parameswaran Nair N, Chalmers L, Peterson GM, Bereznicki BJ, Castelino RL, Bereznicki LR. Hospitalization in older patients due to adverse drug reactions - the need for a prediction tool. Clin Interv Aging. 2016;11:497-505.

18. Belhekar MN, Taur SR, Munshi RP. A study of agreement between the Naranjo algorithm and WHO-UMC criteria for causality assessment of adverse drug reactions. Indian J Pharmacol. 2014;46(1):117-120.

19. Murayama H, Sakuma M, Takahashi Y, Morimoto T. Improving the assessment of adverse drug reactions using the Naranjo algorithm in daily practice: the Japan Adverse Drug Events Study. Pharmacol Res Perspect. 2018;6(1):e00373.

20. Naranjo CA, Busto U, Sellers EM, et al. A method for estimating the probability of adverse drug reactions. Clin Pharmacol Ther. 1981; 30(2):239-245.

21. Griffin FA, Resar RK, Institute for Healthcare Improvement. IHI Global Trigger Tool for Measuring Adverse Events. Second ed. Cambridge, Massachusetts: IHI Innovation Series white paper; 2009. Available from https://oig.hhs.gov/.../IHI\%20Guidance\%20Document $\% 20-\% 20$ Hospital\%20Trigger\%. Accessed August 13, 2018.

22. Saka SA, Oosthuizen F, Nlooto M. Interventions towards reducing adverse drug reactions among geriatric population in Africa: a scoping review of the literature from 1990-2016. PULA: Botswana Journal of African Studies. 2017;31(1):180-194.

23. United Nations DoEaSA. Population Division World Population Ageing 2017-Highlights (ST/ESA/SERA/397). 2017. Available from: http://www.un.org/en/development/desa/population/.../ageing/ WPA2017_Highlights.pdf. Accessed August 13, 2018.

24. do Nascimento MM, Mambrini JV, Lima-Costa MF, Firmo JO, Peixoto SW, de Loyola Filho AI. Potentially inappropriate medications: predictor for mortality in a cohort of community-dwelling older adults. Eur J Clin Pharmacol. 2017;73(5):615-621.

25. Charan J, Biswas T. How to calculate sample size for different study designs in medical research? Indian J Psychol Med. 2013;35(2): 121-126.

26. Charlson M, Szatrowski TP, Peterson J, Gold J. Validation of a combined comorbidity index. J Clin Epidemiol. 1994;47(11):1245-1251.

27. Obreli-Neto PR, Nobili A, de Oliveira Baldoni A, et al. Adverse drug reactions caused by drug-drug interactions in elderly outpatients: a prospective cohort study. Eur J Clin Pharmacol. 2012;68(12): 1667-1676. 
28. Tangiisuran B, Scutt G, Stevenson J, et al. Development and validation of a risk model for predicting adverse drug reactions in older people during hospital stay: Brighton Adverse Drug Reactions Risk (BADRI) model. PLoS One. 2014;9(10):e111254.

29. Conforti A, Costantini D, Zanetti F, Moretti U, Grezzana M, Leone R. Adverse drug reactions in older patients: an Italian observational prospective hospital study. Drug Healthc Patient Saf. 2012;4:75.

30. Alhawassi TM, Krass I, Bajorek BV, Pont LG. A systematic review of the prevalence and risk factors for adverse drug reactions in the elderly in the acute care setting. Clin Interv Aging. 2014;9:2079-2086.

31. Harugeri A, Parthasarathi G, Ramesh M, Guido S, Basavanagowdappa H. Frequency and nature of adverse drug reactions in elderly inpatients of two Indian medical college hospitals. J Postgrad Med. 2011;57(3):189-195.

32. Tosato M, Landi F, Martone AM, et al. Potentially inappropriate drug use among hospitalised older adults: results from the CRIME study. Age Ageing. 2014;43(6):767-773.
33. Price SD, Holman CD, Sanfilippo FM, Emery JD, D’Arcy J. Association between potentially inappropriate medications from the Beers criteria and the risk of unplanned hospitalization in elderly patients. Ann Pharmacother. 2014;48(1):6-16.

34. Montastruc F, Duguet C, Rousseau V, Bagheri H, Montastruc JL. Potentially inappropriate medications and adverse drug reactions in the elderly: a study in a PharmacoVigilance database. Eur J Clin Pharmacol. 2014;70(9):1123-1127.

35. de Jong MR, Van der Elst M, Hartholt KA. Drug-related falls in older patients: implicated drugs, consequences, and possible prevention strategies. Ther Adv Drug Saf. 2013;4(4):147-154.

36. Rosner MH. Acute kidney injury in the elderly. Clin Geriatr Med. 2013;29(3):565-578.

37. Sikdar KC, Dowden J, Alaghehbandan R, Macdonald D, Peter P, Gadag V. Adverse drug reactions in elderly hospitalized patients: a 12-year population-based retrospective cohort study. Ann Pharmacother. 2012 46(7-8):960-971. 


\section{Supplementary materials}

Table SI PIM utilization among participants in Nigeria and South Africa

\begin{tabular}{|c|c|c|}
\hline PIM & Nigeria, n (\%) & South Africa, n (\%) \\
\hline Digoxin & $16(18.6)$ & $9(2.7)$ \\
\hline Amitriptyline & $8(9.3)$ & $10(2.9)$ \\
\hline Pentazocine & $7(8.1)$ & $\mathrm{I}(0.3)$ \\
\hline Glibenclamide & $4(4.6)$ & $3(0.9)$ \\
\hline Chlorpheniramine & $\mathrm{I}(\mathrm{I} .2)$ & $7(2.1)$ \\
\hline Ibuprofen & $\mathrm{I}(\mathrm{I} .2)$ & $22(6.5)$ \\
\hline Diclofenac & $17(19.8)$ & $0(0.0)$ \\
\hline Diazepam & $3(3.5)$ & $0(0.0)$ \\
\hline Bromazepam & $2(2.3)$ & $0(0.0)$ \\
\hline Dextropropoxyphene & $\mathrm{I}(\mathrm{I} .2)$ & $0(0.0)$ \\
\hline Methyldopa & $7(8.1)$ & $0(0.0)$ \\
\hline Metoclopramide & $\mathrm{I}(\mathrm{I} .2)$ & $0(0.0)$ \\
\hline Amiodarone & $0(0.0)$ & $\mathrm{I}(0.3)$ \\
\hline Hyoscine & $0(0.0)$ & $15(4.4)$ \\
\hline Risperidone & $0(0.0)$ & $6(1.8)$ \\
\hline Insulin sliding scale & $0(0.0)$ & $21(6.2)$ \\
\hline Amiodarone and digoxin & $\mathrm{I}(\mathrm{I} .2)$ & $\mathrm{I}(0.3)$ \\
\hline Chlorpromazine and metoclopramide & $\mathrm{I}(\mathrm{I} .2)$ & $0(0.0)$ \\
\hline Diclofenac and pentazocine & $\mathrm{I}(\mathrm{I} .2)$ & $0(0.0)$ \\
\hline Digoxin and bromazepam & $\mathrm{I}(\mathrm{I} .2)$ & $0(0.0)$ \\
\hline Amitriptyline and insulin sliding scale & $0(0.0)$ & $\mathrm{I}(0.3)$ \\
\hline Ibuprofen and promethazine & $0(0.0)$ & $\mathrm{I}(0.3)$ \\
\hline Insulin sliding scale and glibenclamide & $0(0.0)$ & $\mathrm{I}(0.3)$ \\
\hline Insulin sliding scale, digoxin, and amiodarone & $0(0.0)$ & $\mathrm{I}(0.3)$ \\
\hline Digoxin, amiodarone, and methyldopa & $\mathrm{I}(\mathrm{I} .2)$ & $0(0.0)$ \\
\hline \multicolumn{3}{|l|}{ PIM due to disease condition } \\
\hline Tramadol (history of fall without fracture) & $\mathrm{I}(\mathrm{I} .2)$ & $0(0.0)$ \\
\hline \multicolumn{3}{|l|}{ PIM based on kidney function } \\
\hline Spironolactone $(\mathrm{Crcl}<30 \mathrm{~mL} / \mathrm{min})$ & $\mathrm{I}(\mathrm{I} .2)$ & $0(0.0)$ \\
\hline \multicolumn{3}{|l|}{ PIM due to DDI } \\
\hline Lisinopril + Amiloride & $8(1.2)$ & $0(0.0)$ \\
\hline Amitriptyline + Chlorpromazine & $2(1.2)$ & $0(0.0)$ \\
\hline Hyoscine + Chlorpheniramine & $0(0.0)$ & $\mathrm{I}(0.3)$ \\
\hline NSAIDs + Prednisolone & $\mathrm{I}(\mathrm{I} .2)$ & $\mathrm{I}(0.3)$ \\
\hline Total & $86(100.0)$ & $102(100.0)$ \\
\hline
\end{tabular}

Abbreviations: DDI, drug-drug interaction; $\mathrm{Crcl}$, creatinine clearance; PIM, potentially inappropriate medicine. 
Table S2 Potential inappropriate medicines that resulted in ADRs among study participants

\begin{tabular}{l|l|l|l}
\hline PIM in Nigeria & n (\%) & PIM in South Africa & n (\%) \\
\hline Diclofenac & $3(20.0)$ & lbuprofen & $2(20.0)$ \\
Tramadol & I (6.7) & Tramadol & $2(20.0)$ \\
Pentazocine & $2(13.3)$ & Insulin sliding scale & $4(10.0)$ \\
Steroid + Tramadol + Aspirin (>325 mg) & I (6.7) & Prazosin & I (10.0) \\
Amitryptiline & $2(13.3)$ & Lorazepam & I (10.0) \\
Chlorpromazine & $2(13.3)$ & - & - \\
Methyldopa (antihypertensive) & $2(13.3)$ & - & - \\
Digoxin & I (6.7) & - & - \\
Bromazepam & I (6.7) & - & - \\
Total & I5 (I00.0) & Total & $10(100.0)$ \\
\hline
\end{tabular}

Abbreviations: ADRs, adverse drug reactions; PIM, potentially inappropriate medicine.

\section{Publish your work in this journal}

Clinical Interventions in Aging is an international, peer-reviewed journal focusing on evidence-based reports on the value or lack thereof of treatments intended to prevent or delay the onset of maladaptive correlates of aging in human beings. This journal is indexed on PubMed Central, MedLine,
CAS, Scopus and the Elsevier Bibliographic databases. The manuscript management system is completely online and includes a very quick and fair peer-review system, which is all easy to use. Visit http://www.dovepress. $\mathrm{com} /$ testimonials.php to read real quotes from published authors. 